\title{
Renovaskulær sykdom hos barn - sjelden diagnose med få symptomer
}

\begin{abstract}
BAKGRUNN Vi ønsket å kartlegge omfang av, symptomer på, årsaker til og behandling av renovaskulær sykdom hos barn og i tillegg vurdere graden av sekundær organskade på hjerte, nyrer og øyne (endeorganskade).
\end{abstract}

MATERIALE OG METODE Det ble gjort en retrospektiv gjennomgang av data for alle barn i alderen 0-16 år som hadde vært til vurdering for behandlingsresistent hypertensjon i perioden 1998-2013 ved Oslo universitetssykehus, Rikshospitalet.

RESULTATER 21 barn/ungdommer (median alder 8,5 år, 11 jenter) ble vurdert og behandlet for behandlingsresistent hypertensjon i studieperioden. $38 \%$ hadde ingen symptomer på diagnosetidspunktet, $19 \%$ hadde klassiske symptomer på hypertensjon. 15 pasienter fikk invasiv behandling i form av perkutan transluminal renal angioplastikk (PTRA) ( $n=5)$, nefrektomi $(n=6)$, coiling $(n=1)$, autotransplantasjon $(n=1)$ eller en kombinasjon av disse $(n=2)$. Totalt fikk ti av 14 pasienter med registrerte journalopplysninger gunstigere blodtrykk etter behandlingen. Endeorganskade i hjerte og retina ble sett hos henholdsvis $60 \%$ og $50 \%$.

FORTOLKNING Barn med alvorlig forhøyet blodtrykk som følge av renovaskulær sykdom har ofte ingen eller bare uspesifikke symptomer. Ti av 14 fikk lavere blodtrykk etter invasiv behandling, og det var få registrerte komplikasjoner. Invasiv behandling kan vurderes hos barn og ungdom når standardbehandling for hypertensjon ikke er tilstrekkelig.

Hypertensjon forekommer hos $1-5 \%$ av alle barn og ungdommer (1). I motsetning til hos voksne, der essensiell hypertensjon dominerer, er årsakene hos barn oftest sekundære (2). Medfødte eller ervervede nyresykdommer er de hyppigste årsakene til hypertensjon, deretter kommer vaskulære, endokrine eller kardiale årsaker eller sjeldne syndromer. Med den økende fedmeepidemien i samfunnet er det også en økende andel unge med forhøyet blodtrykk relatert til dette (3). Funn av forhøyet blodtrykk i unge år vil predikere forekomsten av hypertensjon som voksen (4).

Renovaskulære tilstander ligger bak $5-10 \%$ av alle hypertensjonstilfeller hos barn (5). I motsetning til hos voksne, der renovaskulær hypertensjon hovedsakelig er forårsaket av arterosklerose, kan flere ulike sykdommer forårsake tilstanden hos barn (6). I vestlige land er fibromuskulær dysplasi ledende årsak, mens Takayasus arteritt dominerer i Afrika og Asia (7-9).

I de fleste tilfeller av renovaskulær sykdom er høyt blodtrykk et tilfeldig funn ved utredning av eventuelle diffuse symptomer eller ved rutinehelsekontroll. Renovaskulær sykdom bør mistenkes når pasienten har svært høyt blodtrykk, endeorganskade eller hvis blodtrykket ikke responderer på behandling med to eller flere blodtrykksmedisiner (5). Hvis blodtrykket ligger langt over 95-prosentilen eller hvis det gjøres ekko coreller øyeundersøkelse av barnet av andre årsaker og man finner noe patologisk som kan oppfattes til å være forårsaket av dette, er det grunn for videre med utredning.
Radiologisk diagnosstisering av renovaskulær sykdom er ofte utfordrende. Digital subtraksjonsangiografi (DSA) er fortsatt gullstandarden, men dopplerultralyd brukes vanligvis til førstelinjescreening. Symptomene ved høyt blodtrykk er ofte upesifiske og sekundære, derfor bør det være lav terskel for å gjøre ultralydundersøkelse hos barn med høyt blodtrykk.

MR-angiografi og CT-angiografi kan også være nyttig for evaluering av renovaskulær hypertensjon $(10,11)$. Førstevalg ved behandling er blodtrykksmedisiner, men blodtrykket er ofte vanskelig å behandle medikamentelt, og derfor er invasiv behandling indisert i enkelte situasjoner. Perkutan transluminal renal angioplastikk (PTRA) kan være teknisk krevende hos små barn. Kirurgiske inngrep ved behandling av renovaskulær hypertensjon inkluderer revaskulering, nefrektomi og autotransplantasjon $(12,13)$.

På grunn av lav forekomst av renovaskulær hypertensjon hos barn ønsket vi i en retrospektiv og deskriptiv studie å få bedre oversikt over tilstanden ved å undersøke hvor mange tilfeller det var i en gitt periode, hva symptomene og årsakene var og hvilken behandling som ble valgt - og med hvilket utfall.

\section{Materiale og metode}

Dette er en retrospektiv, deskriptiv studie utført ved Oslo universitetssykehus, Rikshospitalet. Alle barn (under 16 år) som ble evaluert for behandlingsresistent og/eller renovaskulær hypertensjon i årene 19982013 ble inkludert. Pasientene kom fra hele
Hjørdis Thorsteinsdottir

hjotho@ous-hf.no

Barne- og ungdomsklinikken

Oslo universitetssykehus

Eric Dorenberg

Radiologisk avdeling

Oslo universitetssykehus

\section{Pål-Dag Line}

Avdeling for transplantasjonsmedisin

og

Institutt for klinisk medisin

Universitetet i Oslo

\section{Anna Bjerre}

Barne- og ungdomsklinikken

Oslo universitetssykehus

\section{HOVEDBUDSKAP}

Renovaskulær hypertensjon har uspesifikke symptomer, og forsinket diagnose kan føre til endeorganskade

I vår journalgjennomgang var de vanligste årsakene til tilstanden fibromuskulær dysplasi og Takayasus arteritt

Invasiv behandling for hypertensjon er indisert når behandling med blodtrykksmedisiner ikke er tilstrekkelig

Optimal behandling burde skje i et tverrfaglig team med barnenefrologer, intervensjonsradiologer, karkirurger og barnekirurger 
Tabell 1 Oversikt over underliggende tilstander hos barn som har vært til vurdering for behandlingsresistent hypertensjon ved Oslo universitetssykehus, Rikshospitalet i perioden 1998-2013

\begin{tabular}{lc} 
Underliggende tilstand & Antall \\
Isolert renal arteriestenose & 6 \\
Takayasus arteritt & 4 \\
Fibromuskulær dysplasi & 3 \\
$\begin{array}{l}\text { Nevrofibromatose type 1 } \\
\text { og fibromuskulær dysplasi }\end{array}$ & 2 \\
Schimmelpennings syndrom & 2 \\
Diverse & 4 \\
\hline
\end{tabular}

landet på grunn av Oslo universitetssykehus' landsfunksjon for invasiv behandling av hypertensjon hos barn.

Pasientene ble identifisert ved søk i sykehusets journaler etter følgende ICD-10-koder: I10 (essensiell hypertensjon), I15.0 (renovaskulær hypertensjon), Q27.1 (medfødt stenose av arteria renalis) og Q27.2 (andre medfødte misdannelser i arteria renalis). Da pasientene var blitt identifisert, ble diagnosen bekreftet ved gjennomgang av journalen, og de som enten hadde renovaskulær hypertensjon eller hadde vært gjennom invasiv behandling for høyt blodtrykk, ble inkludert i studien.

Følgende opplysninger ble samlet: blodtrykksmålinger på diagnosetidspunktet, før invasive behandlinger, ved utskrivning og

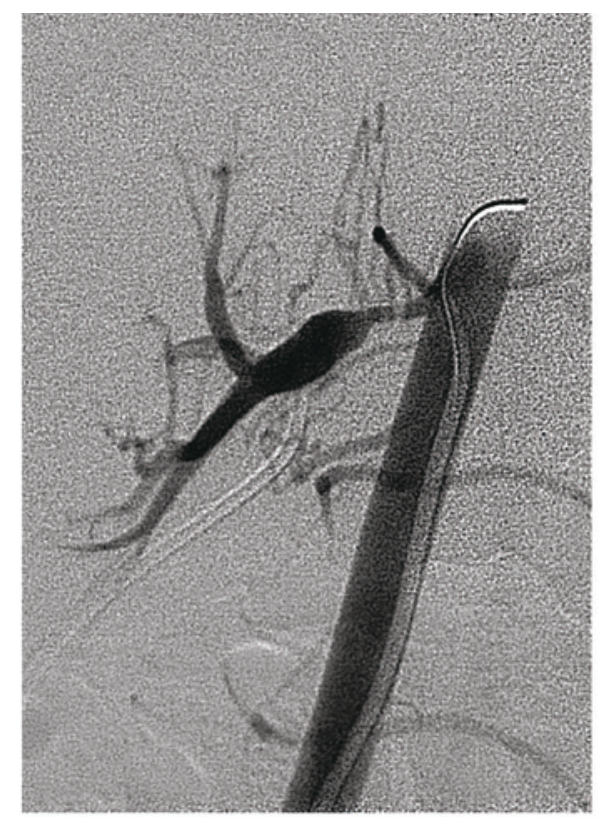

a

Figur 1 a) Avgangsstenose ved høyre nyrearterie. Det foreligger en markert poststenostisk dilatasjon av arte rien like etter forsnevringen. b) Samme arterie etter gjentatt blokking med $5 \mathrm{~mm}$ høytrykksballong med større lumen, men fremdeles stenose i nyrearterien ved alle senere kontroller, antall og type blodtrykksmedisiner ved hver kontroll, antall og type invasiv behandling, komplikasjoner knyttet til invasive behandlinger, symptomer på diagnosetidspunktet, opplysninger om ekkokardiografier, øyeundersøkelser og estimert glomerulær filtrasjonshastighet (eGFR) og underliggende etiologi. Hovedendepunktet var reduksjon i blodtrykk eller antall blodtrykksmedisiner. Blodtrykket var målt med automatiske blodtrykksmålere. Invasive behandlinger inkluderte perkutan transluminal renal angioplastikk, nefrektomi, coiling og autotransplantasjon.

Alle de invasive prosedyrene ble utført i generell narkose. Ved perkutan transluminal renal angioplastikk ble nyrearterier kateterisert med føringskatetre og 0,014' ledesonde. Etter diagnostisk angiografi ble det utført ballongdilatasjon med koronarballonger med diameter 2-4 $\mathrm{mm}$. I tre tilfeller ble skjærende ballonger (cutting balloon) med diameter 3,5-5 $\mathrm{mm}$ brukt.

Det foreligger tilrådning fra personvernombudet ved Oslo universitetssykehus om kvalitetsregisteret som materialet stammer fra. Alle pasientdata ble behandlet anonymt.

\section{Resultater}

\section{Pasientene}

21 barn/ungdommer ble inkludert, hvorav 11 jenter. Median alder på diagnosetidspunktet var 8,5 år (spredning 0-15,8 år).

\section{Diagnoser}

Seks av 21 pasienter hadde isolert renal arteriestenose uten funn av annet underlig-

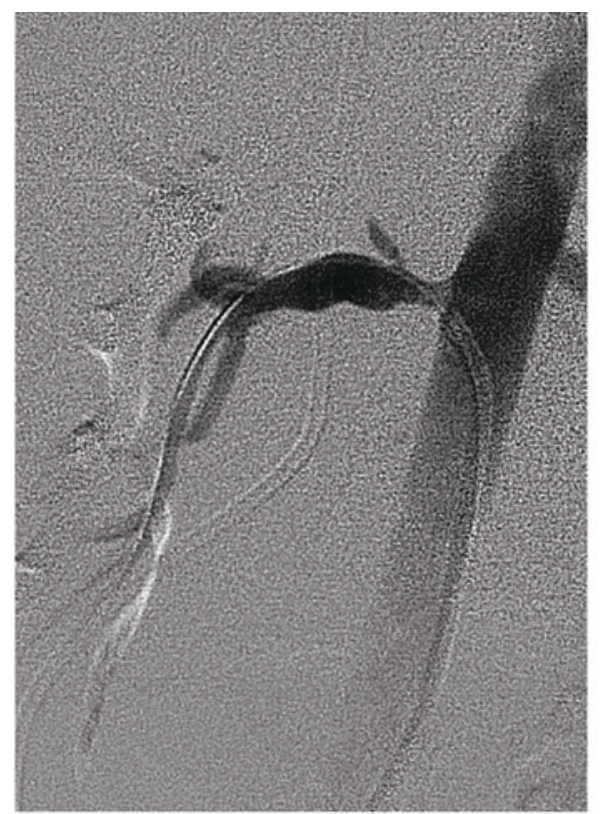

b gende patologisk. De øvrige hadde en tilstand eller en systemsykdom som påvirker nyrearteriene $(\mathrm{n}=12)$ eller nyreparenkymet $(\mathrm{n}=3)$, som vist i tabell 1 .

\section{Symptomer}

Åtte pasienter hadde ingen symptomer hypertensjonen var et tilfeldig funn ved utredning/oppfølging av andre tilstander. Fire pasienter hadde klassiske hypertensjonssymptomer som hodepine og synsforstyrrelser på diagnosetidspunktet. De resterende ni hadde uspesifikke symptomer, som dårlig tilvekst, svimmelhet, hjertesvikt og respiratorisk svikt, ofte som del av en annen underliggende tilstand.

\section{Endeorganskade}

Opplysninger om ekkokardiografi var registrert hos 15 av pasientene, og ni hadde venstre ventrikkel-hypertrofi. Ti pasienter hadde vært til øyeundersøkelse og fem hadde tegn på hypertensiv retinopati. Ingen hadde alvorlig nedsatt nyrefunksjon.

Estimert glomerulær filtrasjonsrate var mellom $39 \mathrm{ml} / \mathrm{min} / 1,73 \mathrm{~m}^{2}$ og $156 \mathrm{ml} / \mathrm{min} /$ $1,73 \mathrm{~m}^{2}$ (median $87 \mathrm{ml} / \mathrm{min} / 1,73 \mathrm{~m}^{2}$ ) før intervensjonen. Registrering av opplysninger om nyrefunksjon etter intervensjonen var mangelfull, men den var bedret etter behandling i de få tilfellene der det fantes opplysninger om dette.

\section{Behandling}

Hos seks av 21 pasienter var invasiv behandling enten ikke indisert eller justering av blodtrykksmedisiner var tilstrekkelig. Tre av disse hadde Takayasus arteritt. Intervensjon var indisert hos de resterende 15 pasientene, hvorav 14 brukte blodtrykksmedisiner før intervensjonen (median to medisiner, spredning 0-5). Alle unntatt to av pasientene hadde blodtrykk over 95-prosentilen (2-70 $\mathrm{mm} \mathrm{Hg}>95$-prosentilen) og syv hadde blodtrykk over 99-prosentilen.

Pasientene ble behandlet med følgende invasive metoder: fem pasienter fikk utført perkutan transluminal renal angioplastikk (fig 1), hos én pasient ble en vaskulær malformasjon i nyren lukket med coil, syv pasienter fikk kirurgisk behandling (seks nefrektomi og én autotransplantasjon) og to pasienter fikk både perkutan transluminal renal angioplastikk og kirurgisk behandling. Hos ti av disse 15 pasientene ble blodtrykket gunstigere etter behandlingen. Resultater for en pasient manglet.

Median tid fra intervensjon til siste kontroll på Rikshospitalet var 16 måneder (spredning 0-48 md.).

\section{Komplikasjoner}

Ingen komplikasjoner ble registrert $\mathrm{i}$ forbindelse med perkutan transluminal renal 
angioplastikk. Det var to kirurgiske komplikasjoner - en postoperativ nyreiskemi og en intraabdominal urinlekkasje som krevde reoperasjon.

\section{Diskusjon}

Denne deskriptive, retrospektive studien viser at ti av 14 barn og ungdommer som har fått invasiv behandling av renovaskulær hypertensjon i Norge, hadde fătt et gunstigere blodtrykk etter behandlingen. På grunn av små tall og den retrospektive designen er det vanskelig å konkludere noe om behandlingseffekten ut ifra disse resultatene.

I større studier utført internasjonalt har man sett på endovaskulære og kirurgiske behandlinger hver for seg. Studier på endovaskulær invensjon har vist bedring (definert som bedring i blodtrykk med/uten medisiner) hos $56-82 \%$ av pasientene (14-17). Gode effekter av stenter i nyrearterier er påvist i utvalgte voksenpopulasjoner (18). Hos barn, derimot, bør stent bare brukes i spesielle tilfeller (19). Ingen av våre pasienter fikk stentbehandling, og tidligere studier har påvist høyere forekomst av restenoser etter stenting (15).

Når det gjelder kirurgi, ble det ved vårt sykehus valgt nefrektomi eller nefrektomi kombinert med autotransplantasjon når kirurgisk behandling var indisert. I andre større studier er det rapportert gode resultater etter kirurgiske inngrep, for eksempel viste en studie bedring i blodtrykket hos alle pasienter etter autotransplantasjon (12).

Tidligere har nefrektomi vært førstevalget, men nå er hovedindikasjonen for nefrektomi fjerning av en dysfunksjonell nyre som driver hypertensjonen (5). Tre av våre pasienter ble behandlet med nefrektomi på grunn av parenkymal sykdom, hvorav kun én viste bedring etter behandlingen. Årsaken til dette kan være at indikasjonen var ikke vurdert riktig eller at det er få pasienter inkludert.

Huang og medarbeidere (20) så på effekten av både autotransplantasjon og perkutan transluminal renal angioplastikk. De rapporterte gunstig utfall hos $95 \%$ ved 30 dagerskontrollen, og ved siste kontroll hadde $91 \%$ av pasientene lavere eller normalt blodtrykk.

Fibromuskulær dysplasi, en ikke-arterosklerotisk og ikke-inflammatorisk vaskulær sykdom, er diagnosert ut fra typisk morfologisk utseende på angiografi og eksklusjon av andre tilstander (21). Fibromuskulær dysplasi er vanligste årsak til renovaskulær hypertensjon hos barn i den vestlige verden, men av våre 21 pasienter var det kun fem der man kunne bekrefte denne tilstanden.

De fleste av pasientene med isolert renal arteriestenose i dette materialet fikk bedre blodtrykkskontroll etter perkutan transluminal renal angioplastikk. To av pasientene $\mathrm{i}$ studien hadde Schimmelpennings syndrom, et nevrokutant syndrom som ofte er assosiert med epilepsi og psykisk utviklingshemning. Hesteskonyre, dobbelt anlegg og vaskulære anomalier i nyrene er også sett ved dette syndromet $(22,23)$.

Endeorganskader er forholdsvis vanlig, opptil $85 \%$ har affeksjon av hjerte, nyrefunksjon eller retina ved diagnosetidspunktet (24). Screening for endeorganskader var utilstrekkelig, kun $71 \%$ og $38 \%$ ble undersøkt med tanke på henholdsvis hjerte- og øyeforandringer. Av disse hadde $60 \%$ affeksjon av hjerte og og $50 \%$ av øye. Ingen av disse hadde alvorlige symptomer, og antageligvis er disse forandringene reversible. Renovaskulær hypertensjon kan være assosiert med mer alvorlig komplikasjoner, som cerebral arteriopati (25), men ingen av pasientene $\mathrm{i}$ vår kohort hadde nevrologiske symptomer.

I overensstemmelse med andre studier (5, 24, 26) var mange pasienter uten symptomer på diagnosetidspunktet. I vår kohort var $38 \%$ symptomfrie, men forholdsvis mange $(43 \%)$ hadde noen uspesifikke symptomer. Dette understreker viktigheten av å måle blodtrykket hos asymptomatiske barn og hos barn med vage symptomer. Blodtrykksmåling er ikke implementert i rutinehelsekontroller av barn, men med tanke på de mulige alvorlige konsekvensene hypertensjon kan ha, kunne det være verdt innsatsen.

Ved MR-angio- og CT-angioundersøkelser får man ofte fremstilt nyrearterier godt. Men digital subtraksjonsangiografi er fortsatt gullstandarden, og i noen tilfeller er det nødvendig for å se på karforandringer intrarenalt. Hos en pasient med nattlig enurese og hypertensjon var det først med angiografi man fikk fremstilt en perifer vaskulær malformasjon i nyren. Denne ble behandlet med coiling, og pasienten ble kvitt både hypertensjonen og enuresen $(27,28)$.

Den største begrensningen ved denne studien er at den er retrospektiv, at problemstillingen er sjelden, populasjonen liten og at det er en del opplysninger som mangler på grunn av ufullstendig registrering. Oppfølgingsperioden er forholdsvis kort fordi mange pasienter ble fulgt videre ved lokalsykehus. Men siden Rikshospitalet har landsfunksjon for den invasive delen av behandlingen, representerer studien hele den norske befolkningen og gir derfor en god oversikt over omfanget av problemstillingen hos barn her i landet.

\section{Hjørdis Thorsteinsdottir (f. 1979)}

er lege i spesialisering og ph.d.-stipendiat innen pediatrisk nefrologi.

Forfatter har fylt ut ICMJE-skjemaet og oppgir ingen interessekonflikter.

\section{Eric Dorenberg (f. 1967)}

er ph.d. og spesialist i radiologi, med spesialkompetanse i intervensjonsradiologi. Han er leder for intervensjonsradiologisk enhet. Forfatter har fylt ut ICMJE-skjemaet og oppgir ingen interessekonflikter.

\section{Pål-Dag Line (f. 1960)}

er professor II i kirurgi, spesialist i generell kirurgi og i karkirurgi, har europeisk sertifisering i abdominal transplantasjonskirurgi og er avde lingssjef. Han er norsk styremedlem i Scandiatransplant.

Forfatter har fylt ut ICMJE-skjemaet og oppgir ingen interessekonflikter.

\section{Anna Bjerre (f. 1957)}

er dr.med., spesialist i pediatri og seksjonsoverlege for pediatrisk nefrologi.

Forfatter har fylt ut ICMJE-skjemaet og oppgir ingen interessekonflikter.

\section{Litteratur}

1. Ahern D, Dixon E. Pediatric hypertension: a gro wing problem. Prim Care 2015: 42: 143-50.

de Swiet M, Dillon MJ. Hypertension in children. BMJ 1989; 299: 469-70

3. Muntner P, He J, Cutler JA et al. Trends in blood pressure among children and adolescents. JAMA 2004: 291: 2107-13

4. Bao W, Threefoot SA, Srinivasan SR et al. Essential hypertension predicted by tracking of elevated blood pressure from childhood to adulthood: the Bogalusa Heart Study. Am J Hypertens 1995; 8: 657-65.

5. Tullus K, Brennan E, Hamilton $G$ et al. Renovascular hypertension in children. Lancet 2008; 371 : 1453-63

6. Sadowski RH, Falkner B. Hypertension in pediatric patients. Am J Kidney Dis 1996; 27: 305-15.

7. Tyagi S, Kaul UA, Satsangi DK et al. Percutaneous transluminal angioplasty for renovascular hypertension in children: initial and long-term results. Pediatrics 1997: 99: 44-9.

8. Bayazit AK, Yalcinkaya F, Cakar N et al. Renovascular hypertension in childhood: a nationwide survey. Pediatr Nephrol 2007; 22: 1327-33.

9. Tullus K. Renovascular hypertension-is it fibromuscular dysplasia or Takayasu arteritis. Pediatr Nephrol 2013; 28: $191-6$.

10. Kurian J, Epelman M, Darge K et al. The role of CT angiography in the evaluation of pediatric renovascular hypertension. Pediatr Radiol 2013; 43: 490-501, quiz 487-9.

11. Chavhan GB, Babyn PS, John P et al. Pediatric Body MR Angiography: Principles, Techniques, and Current Status in Body Imaging. AJR Am J Roentgenol 2015; 205: 173-84.

12. Corbetta JP, Durán V, Burek C et al. Renal autotransplantation for the treatment of renovascular hypertension in the pediatric population. J Pediatr Urol 2011; 7: 378-82.

13. Tullus K. Renal artery stenosis: is angiography still the gold standard in 2011? Pediatr Nephrol 2011. 26: $833-7$

14. Porras D, Stein DR, Ferguson MA et al. Midaortic syndrome: 30 years of experience with medical, endovascular and surgical management. Pediatr Nephrol 2013; 28: 2023-33.

15. Shroff R, Roebuck DJ, Gordon I et al. Angioplasty for renovascular hypertension in children: 20-year experience. Pediatrics 2006: 118: 268-75.

16. Srinivasan A, Krishnamurthy G, Fontalvo-Herazo L et al. Angioplasty for renal artery stenosis in pediatric patients: an 11-year retrospective experience. J Vasc Interv Radiol 2010; 21: 1672-80. 
17. Zhu G, He F, Gu Y et al. Angioplasty for pediatric renovascular hypertension: a 13-year experience. Diagn Interv Radiol 2014; 20: 285-92.

18. Choi SS. Atherosclerotic renal artery stenosis and revascularization. Expert Rev Cardiovasc Ther 2014; 12: 1419-25.

19. Meyers KE, Cahill AM, Sethna C. Interventions for pediatric renovascular hypertension. Curr Hypertens Rep 2014; 16: 422

20. Huang Y, Duncan AA, McKusick MA et al. Renal artery intervention in pediatric and adolescent patients: a 20-year experience. Vasc Endovascular Surg 2007; 41: 490-9.

21. Olin JW, Sealove BA. Diagnosis, management, and future developments of fibromuscular dysplasia. J Vasc Surg 2011; 53: 826-36.e1.

22. Eisen DB, Michael DJ. Sebaceous lesions and their associated syndromes: part II. J Am Acad Dermatol 2009; 61: 563-78, quiz 579-80.

23. Greene AK, Rogers GF, Mulliken JB. Schimmelpenning syndrome: an association with vascular anomalies. Cleft Palate Craniofac J 2007; 44: $208-15$

24. Daniels SR, Loggie JMH, McEnery PT et al. Clinical spectrum of intrinsic renovascular hypertension in children. Pediatrics 1987: 80: 698-704.

25. Willsher A, Roebuck DJ, Ng J et al. How commonly do children with complex cerebral arteriopathy have renovascular disease? Dev Med Child Neurol 2013; 55: 335-40.

26. Humbert J, Roussey-Kesler G, Guerin P et al. Diagnostic and medical strategy for renovascular hypertension: report from a monocentric pediatric cohort. Eur J Pediatr 2015; 174: 23-32.

27. Bjerre A, Erlandsen $\mathrm{M}$, Odland $\mathrm{HH}$ et al. Fourteenyear-old boy with severe hypertension and monosymptomatic nocturnal enuresis (case presentation). Acta Paediatr 2014; 103: 466-7.

28. Bjerre A, Erlandsen M, Odland $\mathrm{HH}$ et al. Fourteenyear-old boy with severe hypertension and monosymptomatic nocturnal enuresis (discussion and diagnosis). Acta Paediatr 2014; 103: 564-5.

Mottatt 18.12. 2016, første revisjon innsendt 24.8. 2016, godkjent 23.12. 2016. Redaktør: Tor Rosness. 